\title{
EFL Reading Comprehension Assessment: Some Grassroots' Voices
}

\section{Lilik Ulfiati}

Universitas Jambi, Jambi, Indonesia

Email: lilik.ulfiati@unja.ac.id

How to cite this paper: Ulfiati, L. (2018). EFL Reading Comprehension Assessment: Some Grassroots' Voices. International Journal of Language Teaching and Education, 2(3), 315-324.

https://doi.org/10.22437/ijolte.v2i3.5123

Accepted: October 18, 2018

Published: November 30, 2018

Copyright (c) International Journal of Language Teaching and Education.

This work is licensed under the Creative Commons Attribution International License (CC BY 4.0).

http://creativecommons.org/licenses/by/4 $.0 /$

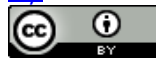

\section{Abstract}

This small-scale case study analyses one of the most debated parts in the field of teaching English as a Foreign Language (EFL); and that is, the teachers and students' perceptions and beliefs of EFL reading comprehension assessment at a major university in Indonesia. The research study involved, randomly selected five EFL teachers and ninety-six EFL students between the period of January and May in Academic Year 2017/2018. Twenty-item Likert scale questionnaires were distributed to the students. Moreover, semi-structured interviewed was done to collect the data from the teachers. Data analysis using descriptive qualitative methods indicate that EFL students need detailed elaboration of their reading practices in answering comprehension questions. Informing their reading results or scores only does not help them very much to practice the reading comprehension skills needed to comprehend the texts. Furthermore, the data indicate that EFL teachers encounter obstacles when they monitor various reading tasks and activities are benefit the students. They tended to assess the students' reading comprehension based on the final correct answers achieved at the end of exercises.

\section{Subject Areas}

Reading Comprehension

\section{Keywords}

EFL, Reading Comprehension Assessment, Likert Scale

\section{Introduction}

Recent trends, the topmost priority of English language teaching in Indonesia has been targeted to the drill and enhancement of learners' four English skills; listening, speaking, reading, writing and three language components namely grammar, vocabulary and pronunciation. Nevertheless, learners' involvement to assess their own reading comprehension skills is still lack of teachers' attention and consideration. Concerning the problem, Sternberg and Grigorenko (2002) explained that in formal approaches to non-dynamic assessment, the items are presented to the examinee who expected to answer 
successively, without taking any kind of feedback or intervention. Later in the future the examiner receives an individual score or a set of scores as the only provided feedback and by that time, the examinee is already studying for one or more future tests. Assessment, in the broad sense, means "any methods used to better understand the current knowledge that a student possesses" (Collins\& O'Brien, 2003). Moreover, Crooks (2001) defines assessment is any process that provides information about the thinking, achievement or progress of students. Because assessment is important in teaching and learning, every teacher should assess his/her students' learning regularly. There are innovations in assessment procedures today, where the change is from summative assessment to formative one. These innovations involve thinking of alternatives, which require questioning the learning process and using learning and assessment activities together rather than habitual testing applications (Charvade, Jahandar \& Khodabandehlou, 2012).

Reading, as an active and interactive process (Nunan, 2001), requires readers must combine bottom-up and top-down process. In this view, besides an interaction between the reader and the content, there is also an interaction between the reader and the writer. This latter interaction, which involves conveying of attitudes and assumptions, is called meta discourse (MD). Hyland (2005) stated that interactive devices available in the texts help the writers deal with the information flow and establish his or her intended meaning. They focus on ways of organizing discourse to predict readers' knowledge and show the writer's assessment of what needs to be made explicit to limit and guide what can be recovered from the text. On the other hand, by using interpersonal devices, the writers interact with the readers, express their views, support or reject an idea or inform the reader of their own personal interpretation and reaction about the content.

Reading comprehension is a complex process involving a combination of text and readers. It is widely reasonable that three key types of reading areas; accuracy (involves phonological and orthographic processing), fluency (includes time), and comprehension (Ahmadi, Hairul, \& Pourhossein, 2012; NICHHD, 2000). Readers, therefore, should consider three important models (bottom-up, top-down and interactive models) in the reading process. Eskey (2005) confirmed that these three models facilitate reading comprehension and help readers to figure out texts and solve their problems while reading. Firstly, bottom-up model confirms that the reading process is supported by each word in the text and a learner decodes each word to understand the meaning. Another, the top-down model points out that reading process is supported mostly by a learner's background knowledge and prior experience. The last model of reading comprehension is interactive model. It refers to the reading process which is supported by an interaction between the text 
information and the learner's background knowledge as well as interaction between different types of metacognitive reading strategies (Grabe, 2004; Eskey, 2005).

English as Foreign Language (EFL) learners at undergraduate level in Indonesia generally have several unfavorable reading habits such as: (1) reading activity not every day, (2) uninterested reading e-text for their daily reading practices, (3) having less than five books to be read every week. The learners' purposes, moreover, to read any English texts are due to doing assignments and their teachers' instruction to do so (Iftanti, 2012). The condition of reading and assessing reading in Indonesia context can be identified that EFL reading practice has been mainly focused on intensive reading. This reading is normally conducted in the classroom, uses a relatively short text accompanied by tasks, and is conducted with the help and/or intervention of a teacher (Cahyono and Widiati, 2006). In addition, Firmanto (2005) found that reading was considered a boring and stressful activity because of some factors such as unsuitable texts (e.g., due to the text length or unfamiliar vocabularies), teachers scarcity in employing pre-reading activities (e.g., explaining some difficult words or activating the students prior knowledge), and monotonous post-reading activities (e.g., answering questions based on the texts and retelling the texts). As such, the exploration of these specific important issues in the Indonesia EFL context is quite crucial and it is hoped that this short research study can shed some light on them.

\section{Literature Review}

Reading comprehension is indeed important competences for successful EFL university learners and they must be provided with this skill. Hosseini and Ghabanchi (2014) confirmed that the last few years have witnessed the paradigm shift in language teaching from the product and transmission to the process and transformation of knowledge. The evaluation process has also undergone a change from a testing culture to an assessment culture (Gipps, 1994). While the former emphasizes the standardization of the test, the latter underlines what students are learning and what they can do with their knowledge (Brown, 2004). As the learners need the reading comprehension competences not only for supporting their academic objectives but also their future professions, they must be familiar with the skills which are very important within their long-term life activities. Therefore, it is necessary for the learners to identify what they learn, how they master the skills and why those skills are essential. By doing so, they can explore the acquired skills and knowledge to analyze, critique, and transform the norms, rule systems which are available in academic contexts or everyday life. Reading skill is one of the key factors for EFL learners' success not only in educational area, but also in 
their social lives and it is also considered as the most essential skill in their academic life (Sajadi \& Oghabi, 2011).

\section{2..1. Models of Reading Process}

Many EFL learners try to learn the target language and read various text genres supporting their academic purposes and daily needs. It is very disappointing if they do not comprehend what they are reading and why the texts are necessary to be figured out. There are three models of reading are widely known in EFL/ ESL contexts: the bottom-up model, the top-down model, and the interactive model (Grabe, 2004; Eskey, 2005). The bottom-up model of reading, essentially, focuses on the texts, teachers, readers begin reading by understanding the words, the letters and gradually improve toward larger linguistic chunks to sentences, and ending in meaning Gough (1972). Ahmadi, Ismail and Abdullah (2013) explained that in this bottom-up model, the whole reading process is based on the words and learners construct meaning from context by recognizing each word. This model believes that readers who utilize this process quickly become skilled readers. The skilled readers have ability to understand frequent letter chunks, prefixes, suffixes, and the original words quickly. So, this ability can release more memory ability in the brain for reading comprehension (Pressley, 2000).

The top-down model views reading as a process of reconstructing the meaning of the texts by fitting them into readers' background knowledge. This model refers to a "notion" driven model where the students' prior information and expectations help them to construct meaning from a reading text, Eskey (2005) explains that the top-down model is based "from brain to text" and focuses on the whole reading process. According to Ahmadi, Hairul, and Pourhossein (2012), the top-down model emphasizes on reading skills like prediction and summarizing as well as anticipating from texts. The top-down model affects both $\mathrm{L} 1$ and $\mathrm{L} 2$ reading instruction in improving the importance of prediction, guessing from the text, and getting the gist of a text's meaning. In this reading process, the readers use their knowledge of vocabularies, sentences, and knowledge of the reading passages to comprehend the texts. Topdown reading is the hypothesis-driven process in which readers, directed by their goals, expectations and strategic processing, actively control the comprehension process (Grabe).

The last reading process is called interactive model which combine both bottom-up and top-down models. Ahmadi, Ismail and Abdulah (2013) explain that this model emphasizes the interrelationship between a reader and the text. Therefore, there is an interaction between the bottom-up and top-down processes and this model indicates that either bottom-up or top-down models can by themselves describe the whole reading process. According to this 
model, readers should interact within the text to comprehend what the passages tell the audience about. Reading is interactive in two senses. On the one hand, there is the interaction between the reader and the text, in that readers use information from their background knowledge as well as information from the text to reconstruct the text information. On the other hand, there is a second level of interaction involving the simultaneous processing interaction between many component skills ranging from rapid lower-level automatic skills to higher-level strategic, comprehension skills. It is important to note that these two levels of interaction are complementary (Kazemi, Hosseini and Kohandani, 2013).

\subsection{Assessing L2 Reading}

Nalliveettil (2014) affirmed that the language instructors should be aware that tasks and activities related to reading process can benefit the students in reading comprehension. To improve reading skills, undergraduate students should be trained to identify the elements that are general across different texts. The instructors, so, have fruitful roles to promote the learners' awareness of reading practices. On the other hand, the undergraduate learners are necessary to be familiar with various reading skills to facilitate them comprehend the English text genres effectively especially in the EFL context. To successfully read, comprehend and respond to the reading, therefore, the reader needs to be equipped with certain skills and ability types Khonamri \& Karimabadi (2015). The instructors of EFL, therefore, should assess regularly what reading tasks and activities being acquired by the students in comprehending the texts. However, Charvade, Jahandar \& Khodabandehlou (2012) stated that a test which is used to evaluate students causes they rely on their memorization ability and reproduce these pieces of information from their memory on the exam to score high and after the exam this information disappeared. This traditional assessment distracts the students from meaningful learning. Also, many other factors may influence students' performances like anxiety, stress.

EFL reading teachers should be made aware of the key role of strategies in EFL reading instruction and consider ways to incorporate them into their syllabi to enhance the efficiency of their teaching. In the case of students, the teachers need to help learners become efficient readers and improve their reading ability. They need to be independent and rely more on certain strategies rather than teacher (Talebinejad, Sadeghdaghighi \& Liaghat, 2015). The teachers should facilitate the leaners with various reading practices which are applicable in their daily reading activities. Formative assessment such as reflective journals and portfolios can be implemented in class for s0074ddeeeudents themselves, peers and teacher to assess to enable students to regulate 
their learning process and the performance of their English study. Such assessing activities also contribute to the development of students' critical thinking skills (Tang, 2016)

\section{Methodology}

This study utilized a mixed method of investigation. A cross-sectional survey was implemented to collect data both quantitatively and qualitatively to triangulate them. The following sections explain the participants, instrument, data collection procedure as well as the data analysis methods.

The present participants in the survey were 96 students majoring in English Education Study Program, Faculty of Teacher Training Education in Indonesia. They were 70 females and 26 male sophomores who were taking their Reading for Academic Purposes course during the second academic semester of 2018. The students had passed their Reading for General Purposes course in which they were learned English basic grammar, general vocabulary, and reading comprehension strategies. Moreover, five teachers of the reading course were involved in this study.

There were two instruments designed to gather the data of the present study namely questionnaire and semi-structured interview. Likert scale questionnaires, twenty-item were distributed students. The questionnaires were completely anonymous. The survey was divided into three sections: demographics, perception of reading assessment and perception about reading skills.

To obtain more in-depth information, semi-structured interviews were carried out to collect qualitative data from the teachers. In this section, interview protocol was arranged comprising the questions to gain the data systematically. Nevertheless, the order of the questions may change, or some questions may be added or omitted (Lodico, et al., 2010). Therefore, questions of interview session related to students and teachers' problems, needs, interests, and opinions on the betterment of reading assessment.

\subsection{Data Collection Procedure}

The data were collected in the second semester of Academic Year 2017/2018 at English Education Study Program, Faculty of Teacher Training and Education, Jambi University. Participants of the present study were selected randomly to respond the questionnaire components. The researcher explained obviously the objective of the research and the purposes of the questionnaires to both teachers and students before distributing them. The questionnaire comprised of three parts relating to the three teaching phases namely preactivities, whilst-activities and post-activities. The participants had to choose strongly to disagree, moderate disagree, slightly disagree, slightly agree, moderate agree and strongly agree to express their perceptions about the reading assessment and the reading skills which were needed to comprehend the English texts. They, therefore, were asked to specify what reading skills were necessary to the students. After the collecting the quantitative data, a group of twenty students were selected randomly from the list of eighty-eight students 
to be interviewed. A semi-structured focus group interview was carried out and the questions concerned about their needs of reading skills, the practices of using reading skills in the classroom, opinions about the betterment of reading assessment, problems in using the reading skills and the like were asked. The interview session was recorded for data analysis.

The questionnaire was distributed to explore the first question of the study, that is, the participants' perceptions towards reading assessment in the contexts where English is a Foreign Language (EFL). Both teachers and students have various responses depending on the item asked. For example, when the teachers, as well as the students, were asked if they believe that reading assessment should be conducted during their reading activities in the classroom, most of the teachers, $85 \%$ and most of the students, $95 \%$, agreed to the item. Nevertheless, when asked if the reading assessment should be carried out by distributing reading tests, the teachers had most of agreement at $90 \%$ although $16 \%$ of the students agreed to the statement, $21 \%$ did not have an opinion and $73 \%$ disagreed with the statement.

Whereas most of the teachers (92\%) and students (88\%) agreed, that in principal, having reading skills will facilitate the readers (students) to identify the detailed information, figure out the meaning based on the contexts, recognize the authors' purposes available in the texts, and distinguish the text patterns used by the writers expressing their ideas in the texts. By having so, the students will be guided to comprehend the reading texts easily. For the teachers, on the other hand, were confirmed that they would like to guide the practice of using the reading skills while the students comprehended the passages. The students did need much more explanation about their reading practices which were difficult and unsatisfied target. Furthermore, most of the students (96\%) felt that they need to be involved in the development and implementation of the reading assessment to help them being familiar with the various reading skills and most teacher participants (4 org/ 90\%) seem do not agree to this. They think that involving the students to assess their reading will take time and need more detailed guidance in the application.

In this part, there were various proposed suggestions chosen from semistructured interviews that were given to selected participants. A large percentage of students (82\%) felt that they need to be clarified why the answers of their reading comprehension questions were wrong and what reading skills are useful to figure out the right ones. They, furthermore, confirmed that it is better if the reading practice done in the classroom is not merely focusing on answering the following comprehension questions. But, they should be trained to analyze why the answers are correct and the others are incorrect. Thus, they could implement their reading skills not only for answering the comprehension questions of the passages but also being applicable for their future professions or daily activities. On the other hand, most of the teachers (82) felt that they need to be a more comprehensive training toward the implementation of reading assessment rubrics and the criteria. 


\section{Findings and discussion}

Although this study has been a small scale one, it analyzed an important aspect of EFL in Indonesia context and that is reading comprehension assessment. The study is aimed at exploring both EFL teachers and students' perceptions or beliefs regarding to reading comprehension assessment at a major university in Indonesia. From the data analysis, it can be figured out that this topic is very complex which has many causes contributing to its overall status. On one hand, we can obviously identify that students agree that there should be clarification or explanation to reading comprehension incorrect answers of their reading comprehension test and model to demonstrate the reading comprehension skills, but, teachers expressed that they should be trained how to go through the reading assessment rubrics and the criteria, especially if they have big class sizes. Besides, the students believe that they are necessary to be familiar with the rubric and what it has expected them to achieve in the reading comprehension skill from the beginning at their study, to be completed with the skills and preparations before the reading examination. Above all, the students' involvement in the assessment process will contribute significantly in improving their reading performance not only for the sake of passing examination but also for their future professions.

\section{References}

[1] Ahmadi, M.R., Ismail, H.N \& Abdullah, M. K. (2013). The importance of metacognitive reading strategy awareness in reading comprehension. English Language Teaching, 6(10). doi:10.5539/elt.v6n10p235

[2] Ahmadi, M. R., Hairul, N. I., \& Pourhossein, A. G. (2012). Impacts of learning reading strategy on students' reading comprehension proficiency. The International Journal of Language Learning and Applied Linguistics World, 1(1), 78-95.

[3] Brown, H. D. (2004). Language assessment: Principles and classroom practices. Longman, Pearson Education, Inc.

[4] Cahyono, B.Y \& Widiati, U. 2006. The teaching of EFL reading in the Indonesian context: The state of the art. TEFLIN, 17(1)

[5] Collins, J., \& OBrien, N. (2003). The greenwood dictionary of education. USA, Westport: Greenwood Press.

[6] Crooks, T. (2001). The validity of formative assessment. Paper presented to the British Educational Research Association Annual Conference, University of Leeds.

[7] Charvade, M. R, Jahandar, S \& Khodabandehlou, M. (2012). The impact of portfolio assessment on EFL learners' reading comprehension ability. English Language Teaching, 5(7).

[8] Eskey, D. E. (2005). Reading in a Second Language. In E. Hinkel (Ed.), Book on Second Language Learning and Teaching (pp. 563-579). Mahwah, NJ: Erlbaum. 
[9] Firmanto, S. O. (2005). Students behavior of reading comprehension: EXpectations and follow up. Paper presented at LIA International conference, Jakarta.

[10] Grabe, W. (2004). Research on teaching reading. Annual Review of Applied Linguistics, 24, 44-69.

[11] Grabe, W. (2009). Reading in a second language: Moving from Theory to Practice. New York, NY: Cambridge University Press.

[12] Gipps, C. (1994). Beyond testing: A theory of educational assessment. London: Falmer Press.

[13] Gough, P. B. (1972). One Second of Reading. In J. F. Kavanaugh, \& I. C. Maltingly (Eds.), Language by Ear and Eye (pp. 331-358). Cambridge, MA: MIT Press.

[14] Hosseini, H \& Ghabanchi, Z. (2014). The effect of portfolio assessment on EFL learners' reading comprehension and motivation. English Language Teaching Journal, 7(5). doi:10.5539/elt. v7n5p110

[15] Hyland, K. (2005). Metadiscourse: Exploring interaction in writing. London: Continuum.

[16] Iftanti, E. (2012). A survey of the English reading habits of EFL students in Indonesia. TEFLIN Journal, 23(2)

[17] Nunan, D. (2001). Second language teaching and learning. Boston. Heinle \& Heinle Publishers.

[18] Sajadi, F., \& Oghabi, M. (2011). Relation between instructors' objective needs and students' subjective needs: The case of Iranian post graduate students. The Asian ESP Journal, 7(4), 123-152.

[19] Kazemi, M., Hosseini, M., \& Kohandani, M. (2013). Strategic reading instruction in EFL contexts. Theory and Practice in Language Studies, 3(12), 2333-2342. doi:10.4304/tpls.3.12.2333-2342

[20] Khonamri, F., \& Karimabadi, M. (2015). C Collaborative strategic reading and critical reading. Theory and Practice in Language Studies, 5(7), 13751382. DOI: http://dx.doi.org/10.17507/tpls.0507.09

[21] Lodico, M. G., Spaulding, D. T., \& Voegtle, K. H. (2010). Methods in educational research: From theory to practice. San Francisco: John Wiley \& Sons.

[22] Nalliveettil, G. M. 2014. Assessing reading strategies of engineering students: Think aloud approach. English Language Teaching Journal, 7(5), doi:10.5539/elt.v7n5p38

[23] National Institute of Child Health and Human Development. (2000). Teaching children to read: An evidence-based assessment of the scientific research literature on reading and its implications for reading instruction. Reports of the subgroups (NIH Publication No. 00-4754). C: U.S. Government Printing Office. 
[24] Pressley, M. (2000). What should comprehension instruction be the instruction of? In M. L. kamli, P. B. Mosenthal, P. D. Pearson, \& R. Barr (Eds.), Handbook of Reading Research. Lawrence Erlbaum Associates, Publishers Mahwah, New Jersey.

[25] Sternberg, R. J., \& Grigorenko, E. L. (2002). Dynamic testing: The nature and measurement of learning potential. Cambridge: Cambridge University Press.

[26] Talebinejad, M. R, Sadeghdaghighi, A, \& Liaghat, F. (2015). Application of reading strategies: A comparative study between Iranian and Indian EFL students. Theory and Practice in Language Studies, 5(2), 356-363. DOI: http://dx.doi.org/10.17507/tpls.0502.16

[27] Tang, L. 2016. Exploration on cultivation of critical thinking in college intensive reading course. English Language Teaching, 9(3). doi: 10.5539/elt.v9n3p18 URL: http://dx.doi.org/10.5539/elt.v9n3p18 